\title{
Relationship between Acute Phase Proteins and Serum Fatty Acid Composition in Morbidly Obese Patients
}

\author{
Ricardo Fernandes, ${ }^{1}$ Bruna Teles Soares Beserra, ${ }^{1}$ \\ Raphael Salles Granato Cunha, ${ }^{2}$ Elaine Hillesheim, ${ }^{2}$ Carolina de Quadros Camargo, ${ }^{1}$ \\ Danielle Cristina Tonello Pequito, ${ }^{3}$ Isabela Coelho de Castro, ${ }^{3}$ Luiz Cláudio Fernandes, ${ }^{3}$ \\ Everson Araújo Nunes, ${ }^{4}$ and Erasmo Benício Santos de Moraes Trindade ${ }^{5}$
}

${ }^{1}$ Post-Graduate Program in Nutrition, Federal University of Santa Catarina, Trindade Campus, 88040-900 Florianópolis, SC, Brazil

${ }^{2}$ Graduate Program in Nutrition Center, Federal University of Santa Catarina, Trindade Campus, 88040-900 Florianópolis, SC, Brazil

${ }^{3}$ Department of Physiology, Biological Sciences Building, Centro Politécnico Campus, Federal University of Paraná, Avenida Cel Francisco H dos Santos, s/n, 81530-900 Jardim das Américas, PR, Brazil

${ }^{4}$ Physiological Sciences Department, Biological Sciences Center, Federal University of Santa Catarina, Trindade Campus, 88040-900 Florianópolis, SC, Brazil

${ }^{5}$ Department of Nutrition and Post-Graduate Program in Nutrition, Federal University of Santa Catarina, Trindade Campus, 88040-900 Florianópolis, SC, Brazil

Correspondence should be addressed to Erasmo Benício Santos de Moraes Trindade; erasmotrindade@gmail.com

Received 31 January 2013; Accepted 1 May 2013

Academic Editor: Sudhir Srivastava

Copyright ( 2013 Ricardo Fernandes et al. This is an open access article distributed under the Creative Commons Attribution License, which permits unrestricted use, distribution, and reproduction in any medium, provided the original work is properly cited.

Background. Obesity is considered a low-grade inflammatory state and has been associated with increased acute phase proteins as well as changes in serum fatty acids. Few studies have assessed associations between acute phase proteins and serum fatty acids in morbidly obese patients. Objective. To investigate the relationship between acute phase proteins (C-Reactive Protein, Orosomucoid, and Albumin) and serum fatty acids in morbidly obese patients. Methods. Twenty-two morbidly obese patients were enrolled in this study. Biochemical and clinical data were obtained before bariatric surgery, and fatty acids measured in preoperative serum. Results. Orosomucoid was negatively correlated with lauric acid $(P=0.027)$ and eicosapentaenoic acid $(\mathrm{EPA})(P=0.037)$ and positively with arachidonic acid $(\mathrm{AA})(P=0.035), \mathrm{AA} / \mathrm{EPA}$ ratio $(P=0.005)$, and $\mathrm{n}-6 / \mathrm{n}-3$ polyunsaturated fatty acids ratio $(P=0.035)$. C-Reactive Protein (CRP) was negatively correlated with lauric acid $(P=0.048)$, and both CRP and CRP/Albumin ratio were negatively correlated with margaric acid $(P=0.010, P=0.008$, resp.). Albumin was positively correlated with EPA $(P=0.027)$ and margaric acid $(P=0.008)$. Other correlations were not statistically significant. Conclusion. Our findings suggest that serum fatty acids are linked to acute phase proteins in morbidly obese patients.

\section{Introduction}

Obesity is a chronic multifactorial disease, among which are environmental, nutritional, and genetic factors, characterized by the excessive accumulation of body fat, causing damage to health [1].

Data from World Health Organization [1] have shown that obesity has more than doubled since 1980s, reaching epidemic proportions. In 2008, approximately 1.5 billion adults were overweight and of these, at least 200 million were obese men and 300 million were obese women. This represents a serious public health problem, because obese subjects are more susceptible to the development of obesity-related diseases such as hypertension, diabetes mellitus, congestive heart failure, asthma, sleep apnea, and venous thromboembolism [2]. In cases of failure in clinical treatment, bariatric surgery is a consistent therapeutic resource, providing reduction in mortality and improvement of clinical comorbidities $[3,4]$. 
In obese subjects there is an increase in the secretion of inflammation-related proteins by adipose tissue, such as cytokines and acute phase proteins, which increase the production and circulation of other inflammatory mediators, contributing to the formation of a low-grade chronic inflammatory state $[5,6]$.

In addition, dietary fatty acids are among the important factors of low-grade inflammation. The serum fatty acids in humans can be used as a biomarker of fatty acid intake [7, 8] and have been involved with the development of chronic diseases, including metabolic syndrome and obesity $[9,10]$. High proportions of saturated fatty acids (SFA) and low proportions of n-3 polyunsaturated fatty acids (PUFA) and monounsaturated fatty acids (MUFA) are associated with obesity $[11,12]$.

A limited number of studies have verified the association between serum fatty acids composition and acute phase proteins, all of them in nonobese subjects [13-18]. These studies showed that serum CRP concentrations were inversely associated with PUFA, such as alpha-linolenic acid [13-15], linoleic acid [16-18], eicosapentaenoic acid (EPA) [14, 16], and docosahexaenoic acid (DHA) [16], while SFA and MUFA such as palmitic acid [13], palmitoleic acid [17, 18], and oleic acid [17] were positively associated with CRP. Regarding albumin and ORM, there is a lack of information about the relationship between serum fatty acids and these acute phase proteins, both in obese and nonobese subjects.

Based on the above considerations, the aim of this study was to investigate the relationship between acute phase proteins (C-Reactive Protein, Orosomucoid and Albumin) and serum fatty acids in morbidly obese patients. Our hypothesis is that SFA will be positively correlated with positive acute phase proteins, while PUFA will demonstrate an opposite behavior.

\section{Materials and Methods}

2.1. Participants. From August to November 2011, a convenience sample of patients who were scheduled to undergo Roux-en-Y gastric bypass $(n=28)$ in the University Hospital of the Federal University of Santa Catarina (Florianópolis, Brazil) was invited to participate in this cross-sectional study.

Inclusion criteria for participation were age $>18$ years, body mass index $(\mathrm{BMI})>40 \mathrm{~kg} / \mathrm{m}^{2}$ or $\mathrm{BMI}>35 \mathrm{~kg} / \mathrm{m}^{2}$ with at least one comorbidity (e.g., hypertension, diabetes), and previously dietary and pharmacological treatment failure. Exclusion criteria for participation were significant intellectual limitations without adequate family support, uncontrolled psychiatric disorder, alcohol or drug dependency, current treatment with antibiotics and/or anti-inflammatory drugs, trauma, surgery or hospitalization in the last 30 days, and presence of cancer and/or genetic diseases.

Patients received interdisciplinary education about risks and changes in habits inherent in a major surgery on the digestive tract and the need for postoperative lifestyle changes. All patients underwent surgical, endocrinological, psychological, and nutritional evaluations before surgery.
This study was approved by the Ethics Committee on Research with Human Beings of this institution, which is in accordance with the Helsinki's World Medical Declaration [19]. All eligible patients were invited to participate and those interested signed an Informed Consent Form.

2.2. Blood Collection. Blood samples $(10 \mathrm{~mL})$ were collected in the morning, before surgery procedure, after overnight fast of 8 to 12 hours. A cubital venipuncture was performed in the region of the forearm by a trained professional. Samples were collected in tubes with serum separator gel. They were left at room temperature for 30 minutes and then centrifuged at $2500 \mathrm{RCF}(\mathrm{g})$ for 10 to 15 minutes to isolate serum. An aliquot was stored in $\mathrm{a}-80^{\circ} \mathrm{C}$ freezer until analysis.

2.3. Assessment of Biochemical Parameters. Serum concentrations of CRP and ORM were determined by immunonephelometry (Siemens Dade Behring Inc., Newark, DE, USA) [20] and Albumin was determined by automated colorimetric method (Siemens Healthcare Diagnostics Inc., Newark, DE, USA) [21]. CRP concentrations were expressed as $\mathrm{mg} / \mathrm{L}$, $\mathrm{ORM}$ in $\mathrm{mg} / \mathrm{dL}$, and Albumin in $\mathrm{g} / \mathrm{dL}$.

CRP/Albumin ratio proposed by Correa et al. [22] was used to evaluate inflammatory and nutritional prognosis of patients, classified as follows: no risk $<0.4$; low risk $=0.4-1.2$; medium risk $=1.2-2.0$ and high risk $>2.0$. This index represents a simplification of the Prognostic Inflammatory and Nutritional Index proposed by Ingenbleek and Carpentier [23].

2.4. Serum Fatty Acid Profile. Serum lipids were extracted using chloroform: methanol (2:1, vol: vol) according to the method described by Folch et al. [24]. Then, the lipid extracts were suspended in methanol and $\mathrm{pH}$ adjusted to $\geq 12$ with $5 \mathrm{~mol} / \mathrm{L} \mathrm{NaOH}$. The aqueous solution was acidified with hydrochloric acid $(\mathrm{pH} \leq 3)$ and subjected to a new lipid extraction by hexane, followed by evaporation of gas $\mathrm{N}_{2}$ at $37^{\circ} \mathrm{C}$. Fatty acids were derivatized with 4-bromomethyl7-coumarin and acetonitrile and then separated on a high performance liquid chromatography using an octadecylsilica column $(25 \mathrm{~cm} \times 4.6 \mathrm{~mm}$ i.d.; particle size $5 \mathrm{~mm})$. The flow rate of $1 \mathrm{~mL} / \mathrm{min}$ of acetonitrile/water $(77: 23, \mathrm{v} / \mathrm{v})$ was applied. The standard mixture of fatty acids was obtained from Sigma Chemical Co. (St. Louis, MO, USA). The elution sequence and limit of detection were determined. The minimum limit of quantification of the fatty acids ranged from 1 to $10 \mathrm{ng}$. Fatty acid derivatives were detected by fluorescence ( $325 \mathrm{~nm}$ excitation, $398 \mathrm{~nm}$ emission), and data was integrated and analyzed by the workstation Pro-Star LC 6.0. The amounts of fatty acids were expressed as the percentage of the sum of the fatty acids that were analysed.

2.5. Anthropometry Measurements. Presurgical height and weight were obtained with participants wearing light clothing and no shoes, by a nutritionist, following standardized techniques [25]. Weight was measured using an electronic scale platform (Welmy, Santa Bárbara d'Oeste, São Paulo, Brazil), with a capacity of $300 \mathrm{~kg}$ and accuracy of $0.050 \mathrm{~kg}$. Height 
was measured by a stadiometer coupled to platform with a capacity of $2.00 \mathrm{~m}$ and accuracy of $0.5 \mathrm{~cm}$. BMI was calculated as weight $(\mathrm{kg}) /$ height $^{2}(\mathrm{~m})$ and classified according to World Health Organization [26].

2.6. Assessment of Other Variables. The following variables were also evaluated: patient age (years), gender, smoking status, use of medication, comorbidities, length of hospital stay, and need for ventilatory support. All data were collected from medical records. With regard to smoking status, those who had smoked $\geq 100$ cigarettes during their entire life and currently smoked every day or some days were considered current smokers. Former smokers were those who reported smoking $\geq 100$ cigarettes during their lifetime and currently do not smoke. Nonsmokers were those who reported never having smoked 100 cigarettes during their entire life [27].

2.7. Data Analysis. Qualitative variables were described through absolute and relative frequencies, while quantitative variables were described using mean and standard deviation values or median and interquartile range values. Normality of variables was assessed by Shapiro-Wilks test. The correlation between fatty acid composition and acute phase proteins was investigated by Pearson's (parametric variables) or Spearman's (nonparametric variables) correlation analysis. A value of $P<$ 0.05 was taken to indicate statistical significance. The database was typed in Microsoft Office Excel, and statistical analysis was conducted in STATA statistical software, version 11.0 (STATA corporation, College Station, TX, USA).

\section{Results}

Of the 28 patients initially recruited, six were excluded for being in treatment with anti-inflammatory/antibiotic drugs $(n=4)$ or refused to participate $(n=2)$. Finally, the study involved 22 patients with mean age of $37.3 \pm 8.8$ years, mean weight of $131.4 \pm 16.5 \mathrm{~kg}$, and mean BMI of $47.7 \pm 4.4 \mathrm{~kg} / \mathrm{m}^{2}$. The average length of hospital stay was $5.2 \pm 1.3$ days and nobody needed to use ventilatory support.

Table 1 summarizes characteristics of the subjects studied. The majority of study participants were female, nonsmokers, presented classical obesity-related comorbidities, such hypertension and diabetes, and all patients used some type of medication. It is worth mentioning that due to the selection criteria, none of them made use of antibiotics or antiinflammatory drugs.

Biochemical parameters of the subjects studied are shown in Table 2. Regarding the risk of inflammatory and nutritional complications using CRP/Albumin ratio, most patients were at high risk ( $n=18)$. Only one patient was classified as medium risk and three as low risk.

In relation to serum fatty acid composition, one sample was discarded due to problems in its analysis; therefore only 21 samples were processed. Serum proportions of fatty acids are presented in Table 3. The distribution pattern showed a high proportion of SFA (48\%) and MUFA (35.9\%) and a minor proportion of PUFA (16.1\%), especially EPA (C20:5 n3 ) and DHA (C22:6 n-3).
TABLE 1: Characteristics of morbidly obese subjects studied $(n=22)$.

\begin{tabular}{lc}
\hline & $n(\%)$ \\
\hline Female & $18(81.8)$ \\
Male & $4(18.2)$ \\
Comorbidities & \\
$\quad$ Hypertension & $12(54.5)$ \\
Diabetes mellitus & $5(22.7)$ \\
Hypothyroidism & $3(13.6)$ \\
Cholelithiasis & $1(4.6)$ \\
Gastritis & $1(4.6)$ \\
Smoking status & \\
Non- & $18(81.8)$ \\
Former & $3(13.6)$ \\
Current & $1(4.5)$ \\
Use of medication & \\
Antihypertensive drugs & $9(40.9)$ \\
Thiazide diuretics & $4(18.2)$ \\
Oral hypoglycemic agents & $3(13.6)$ \\
Thyroid hormones & $3(13.6)$ \\
Insulin & $2(9.1)$ \\
Proton pump inhibitors & $1(4.6)$ \\
\hline
\end{tabular}

TABLE 2: Biochemical parameters of morbidly obese subjects studied $(n=22)$.

\begin{tabular}{lccc}
\hline Parameter & Mean \pm SD & Median & Min-Max \\
\hline Albumin $(\mathrm{g} / \mathrm{dL})$ & $3.6 \pm 0.4$ & 3.7 & $2.9-4.1$ \\
CRP $(\mathrm{mg} / \mathrm{L})$ & $14.7 \pm 7.6$ & 14.4 & $3.3-30.7$ \\
ORM $(\mathrm{mg} / \mathrm{dL})$ & $107.7 \pm 21.8$ & 108.0 & $70.7-158.0$ \\
CRP/Albumin & $4.2 \pm 2.3$ & 4.3 & $0.8-8.3$ \\
\hline
\end{tabular}

CRP: C-Reactive Protein; ORM: Orosomucoid; SD: standard deviation; Min: minimum; Max: maximum.

Correlations between fatty acid composition and acute phase proteins (ORM, CRP, Albumin, and CRP/Albumin ratio) were analyzed (Table 4 ). In morbidly obese patients, the concentrations of ORM were significantly and negatively correlated with the proportion of lauric acid $(P=0.027)$ and EPA $(P=0.037)$ and positively with arachidonic acid (AA) $(P=0.035)$, AA/EPA ratio $(P=0.005)$, and $n-6 / n-$ 3 ratio $(P=0.035)$. Likewise, $\mathrm{CRP}$ was significantly and negatively correlated with lauric acid $(P=0.048)$, and both CRP and CRP/Albumin ratio were negatively correlated with margaric acid $(P=0.010, P=0.008$, resp.). Albumin was positively correlated with EPA $(P=0.027)$ and margaric acid $(P=0.008)$. Other correlations of fatty acids with the variables reported in Table 4 were not statistically significant.

\section{Discussion}

The findings in the present study are consistent with the hypothesis that EPA (n-3 PUFA) has anti-inflammatory properties while AA (n-6 PUFA) showed an opposite behavior [28-30]. In addition, we found significant and negative correlations between margaric acid and acute phase proteins, 
TABLE 3: Serum fatty acid composition (\%) of morbidly obese subjects studied $(n=21)$.

\begin{tabular}{lcc}
\hline Fatty acid & $\begin{array}{c}\text { Mean } \pm \text { SD } \\
\text { (\% of total fatty acids) }\end{array}$ & Min-Max \\
\hline SFA & & \\
C12:0 (lauric acid) & $17.1 \pm 3.4$ & $8.7-22.3$ \\
C14:0 (myristic acid) & $4.8 \pm 0.7$ & $2.9-6.0$ \\
C16:0 (palmitic acid) & $21.5 \pm 3.3$ & $16.8-23.9$ \\
C17:0 (margaric acid) & $0.4(0.3-1.0)^{\mathrm{a}}$ & $0.1-1.0$ \\
C18:0 (stearic acid) & $4.1 \pm 1.2$ & $2.3-6.5$ \\
MUFA & & \\
C16:1 n-7 (palmitoleic acid) & $20.7 \pm 3.1$ & $14.2-25.3$ \\
C18:1 n-9 (oleic acid) & $15.2 \pm 2.0$ & $11.2-16.6$ \\
n-3 PUFA & & \\
C20:5 n-3 (EPA) & $1.2(1.1-1.7)^{\mathrm{a}}$ & $0.9-1.9$ \\
C22:6 n-3 (DHA) & $2.8 \pm 0.5$ & $1.9-3.1$ \\
n-6 PUFA & & \\
C18:2 n-6 (linoleic acid) & $3.8(3.0-4.4)^{\mathrm{a}}$ & $2.4-4.8$ \\
C20:4 n-6 (AA) & $8.2 \pm 2.1$ & $5.1-8.9$ \\
n-6/n-3 & $2.9 \pm 0.8$ & $1.5-5.0$ \\
AA/EPA & $6.5 \pm 2.5$ & $3.4-12.5$ \\
PUFA/SFA & $0.3 \pm 0.1$ & $0.2-0.5$ \\
\hline AA & &
\end{tabular}

AA: arachidonic acid; EPA: eicosapentaenoic acid; DHA: docosahexaenoic acid; MUFA: monounsaturated fatty acids; PUFA: polyunsaturated fatty acids; SFA: saturated fatty acids SD: standard deviation. Min: minimum; Max: maximum.

${ }^{a}$ Median (interquartile range).

except for ORM, while lauric acid was significantly and negatively correlated with positive acute phase proteins only.

The results are consistent with other studies that found high concentrations of CRP in obese subjects [31-33]. Chen et al. [32] suggested the use of CRP as a clinical indicator of the chronic inflammatory state in morbidly obese subjects. It should be highlighted that synthesis of CRP is directly related to the BMI [34]. Therefore, weight gain results in high CRP concentrations, which explains the high concentrations of CRP found in this study. According to the American Heart Association and Centers for Disease Control and Prevention (AHA-CDC), subjects with CRP $>3 \mathrm{mg} / \mathrm{L}$ are at high risk for developing cardiovascular diseases [35]. In this work, all patients had CRP concentrations above $3 \mathrm{mg} / \mathrm{L}$, a result that reinforces the use of CRP as a risk indicator in obese patients. Likewise, most participants $(n=18)$ showed high risk of nutritional and inflammatory complications according to the $\mathrm{CRP} /$ Albumin ratio. It is worth noting that this result was due to the high values of CRP since most patients were within the reference range of albumin [21].

Regarding Albumin, Schweiger et al. [36] found concentrations of this protein within the reference range in obese patients, similar to the results of this study, indicating that the low-grade inflammatory state would not be sufficient to
TABLE 4: Correlations between the relative contents of serum fatty acids and acute phase proteins in morbidly obese subjects studied $(n=21)$.

\begin{tabular}{|c|c|c|c|c|}
\hline Fatty acids & ORM & CRP & Albumin & $\begin{array}{c}\text { CRP/ } \\
\text { Albumin }\end{array}$ \\
\hline \multicolumn{5}{|l|}{ SFA } \\
\hline $\mathrm{C} 12: 0$ (lauric acid) $^{\mathrm{a}}$ & $-0.48^{*}$ & $-0.44^{*}$ & 0.07 & -0.38 \\
\hline C14:0 (myristic acid) ${ }^{\mathrm{a}}$ & -0.26 & -0.29 & -0.21 & -0.19 \\
\hline C16:0 (palmitic acid) ${ }^{\mathrm{a}}$ & 0.20 & 0.10 & -0.20 & 0.14 \\
\hline $\mathrm{C} 17: 0$ (margaric acid) $^{\mathrm{b}}$ & -0.09 & $-0.57^{*}$ & $0.58^{*}$ & $-0.59^{*}$ \\
\hline 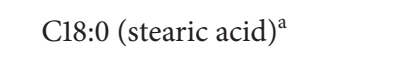 & -0.19 & 0.03 & 0.11 & 0.03 \\
\hline \multicolumn{5}{|l|}{ MUFA } \\
\hline C16:1 n-7 (palmitoleic acid) ${ }^{a}$ & -0.10 & 0.24 & 0.08 & 0.18 \\
\hline C18:1 n-9 (oleic acid) ${ }^{a}$ & 0.14 & 0.23 & -0.07 & 0.19 \\
\hline \multicolumn{5}{|l|}{ n-3 PUFA } \\
\hline $\mathrm{C} 20: 5 \mathrm{n}-3(\mathrm{EPA})^{\mathrm{b}}$ & $-0.46^{*}$ & -0.29 & $0.51^{*}$ & -0.33 \\
\hline $\mathrm{C} 22: 6$ n-3 (DHA) ${ }^{\mathrm{a}}$ & -0.07 & -0.14 & 0.06 & -0.12 \\
\hline \multicolumn{5}{|l|}{ n-6 PUFA } \\
\hline C18:2 n-6 (linoleic acid) ${ }^{b}$ & 0.19 & 0.41 & -0.41 & 0.39 \\
\hline C20:4 n-6 (AA) ${ }^{a}$ & $0.46^{*}$ & 0.01 & -0.11 & 0.01 \\
\hline$n-6 / n-3^{a}$ & $0.46^{*}$ & 0.26 & -0.24 & 0.25 \\
\hline $\mathrm{AA} / \mathrm{EPA}^{\mathrm{a}}$ & $0.59^{*}$ & 0.22 & -0.32 & 0.23 \\
\hline PUFA/SFA ${ }^{\mathrm{a}}$ & 0.42 & 0.22 & -0.12 & 0.20 \\
\hline
\end{tabular}

AA: arachidonic acid; CRP: C-reactive Protein; EPA: eicosapentaenoic acid; DHA: docosahexaenoic acid; ORM: orosomucoid; MUFA: monounsaturated fatty acids; PUFA: Polyunsaturated fatty acids; SFA: saturated fatty acids. ${ }^{*} P<0.05,{ }^{\mathrm{a}}$ Pearson's correlation, ${ }^{\mathrm{b}}$ Spearman's correlation.

promote a significant change in serum albumin. However, other investigations have observed a significant number (>10\%) of obese patients with low serum albumin concentrations [37, 38]. Turner et al. [39] conducted a study in over 32,000 patients undergoing laparoscopic gastric bypass and concluded that preoperative serum albumin was considered the strongest predictor for morbidity and mortality in the first 30 days after surgery. Although many factors influence the development of complications after bariatric surgery and the majority of patients in this study showed a high risk of inflammatory and nutritional complications according to the CRP/Albumin ratio, no patient underwent ventilatory support or presented any immediate postoperative complication. Possibly, part of this positive result is due to normal concentrations of albumin.

With regard to ORM, due to the slow increase in the synthesis after a stimulus and its immunomodulatory activity in situations of prolonged stress (e.g., obesity), this marker can be used as an indicator of chronic inflammation [40]. A limited number of studies have shown high concentrations of ORM in morbidly obese patients [41-43]. Like PCR, ORM shows positive correlation with BMI and adipose tissue [44], while the loss of weight leads to significant reduction of this protein [41-43]. In obese mice, ORM suppressed proinflammatory gene expression and pathways such as NF- $\kappa \mathrm{B}$ 
and mitogen-activated protein kinase signaling and reactive oxygen species generation, protecting adipose tissue from excessive inflammation and from metabolic disfunction [40]. Thus, it is important to encourage studies that explore the role of ORM in human obesity and other metabolic diseases.

About the fatty acid composition in human subjects, Hodson et al. [45] performed a compilation of nine studies on total plasma fatty acid composition in nonobese people, and, among the fatty acids analyzed, linoleic acid, palmitic acid, and oleic acid had the highest proportions, respectively. In the present study, palmitic acid, palmitoleic acid, and lauric acid showed the highest proportions, respectively. Studies with obese people showed a similar pattern compared to the results found in the current work, with high amounts of SFA and low amounts of PUFA $[11,12]$.

Nevertheless, the proportions of lauric acid and palmitoleic acid observed are unusual and require discussion. The first reason why these acids showed high proportions could be due to the fact that fatty acids were expressed as relative amounts (as proportions of the total amount of fatty acids). As a result, if the relative content of one fatty acid decreases, the relative content of other fatty acids will increase. Because PUFA showed the lowest proportion in the study (16.1\%) compared to the proportions of SFA (48\%) and MUFA (35.9\%), it is possible that the relative content of lauric and palmitoleic acids has increased. The second reason could be due to the desaturation processes that synthesise a variety of fatty acid species. Stearoil CoA Desaturase 1 (SCD1) is a enzyme that catalyzes the biosynthesis of MUFA from dietary or de novo synthesized SFA precursors. High SCD1 expression is directly correlated with metabolic diseases, such as obesity [46]. Thus, it should be considered that the palmitoleic acid in serum can be derived, in part, from palmitic acid. The last reason is related to the type of diet that the patients were instructed to follow prior to surgery. As described previously, all patients received interdisciplinary education, including dietary guidelines. According to these guidelines, all patients should reduce the caloric intake, especially lipids. In a controlled dietary intervention for six weeks, the effects of a moderate- and low-fat diet on the fatty acid composition of plasma were investigated [47]. After a low-fat diet, there is a notable increase in the palmitoleic acid content and a significant decrease in total PUFA content of plasma lipids. Moreover, other investigations revealed that the content of total plasma fatty acids is a marker of habitual dietary intake $[48,49]$. Thus, the findings of the current work may reflect the pattern of habitual dietary intake of the patients and could also partly explain the high proportions of lauric acid and palmitoleic acid in total serum lipids, although dietary surveys have not been conducted to confirm this hypothesis.

Regarding the role of fatty acids in inflammation, controversial data are available regarding the proinflammatory role of SFA. It has been shown that lauric acid directly stimulates toll-like receptors $2 / 4[50,51]$ and induce secretion of proinflammatory cytokines in macrophages and dendritic cells. In contrast, Murumalla et al. [30] have shown that lauric and palmitic acids were not able to induce inflammation on primary culture of human adipose tissue and mature adipocytes. Similarly, Erridge and Samani [52] demonstrated that SFAs, (lauric, myristic, palmitic, and stearic acids) were not able to induce inflammation. These findings come close to the correlations found, wherein SFA did not correlate significantly and positively with positive acute phase proteins, which are related to proinflammatory activity.

Among the fatty acids analyzed, margaric acid showed the highest correlation coefficients. Evidence is limited in obese patients regarding the associations of margaric acid with inflammatory markers. Warensjö et al. [53] observed that the proportions of margaric acid in serum phospholipids were significantly correlated with inflammatory markers, suggesting negative relationships with insulin resistance syndrome and risk of developing myocardial infarction. Maruyama et al. [54] reported that margaric acid was higher in women with than without metabolic syndrome and was correlated negatively with body fat percentage. Wang et al. [55] observed that among overweight, but not normal weight adolescents, high levels of margaric acid were associated with low levels of CRP. Despite the potential benefical effects of margaric acid, to our knowledge, there is no evidence showing whether this acid is involved in an anti-inflammatory cell signaling network and the underliyng mechanisms. In addition, there is no evidence linking ORM and albumin with margaric acid in obese subjects. Importantly, due to possible anti-inflammatory effects of margaric acid and its inverse correlation with proinflammatory markers and obesity-related comorbidities, a positive relationship is expected with albumin and a negative relationship with ORM and CRP. However, further studies are warranted, in order to elucidate the relationship between margaric acid, weight status, and inflammation.

As expected, EPA was found to be inversely correlated with ORM and directly correlated with albumin. Differently, AA and n-6/n-3 and AA/EPA ratios were positively correlated with ORM. With regard to EPA, previous studies have described a variety of mechanisms by which EPA may influence inflammatory pathways and exert protective effects [28]. In in vitro studies, EPA directly downregulates inflammatory genes by suppressing nuclear factor- $\kappa \mathrm{B}$ activity [56] probably through activation of peroxisome proliferatoractivated receptors (PPAR) [57]. EPA, as well as AA, plays an important role in regulating the immune system, acting as precursors for the synthesis of eicosanoids, including prostaglandins, thromboxanes, and leukotrienes [29]. In general, AA-derived eicosanoids, which generally exhibit proinflammatory actions, are more potent than mediators derived from EPA. However, EPA-derived eicosanoids may antagonise the proinflammatory actions of AA [29]. In this sense, it is expected that positive acute phase proteins, such as ORM, exhibit a positive correlation with AA and a negative correlation with EPA.

Similar to CRP/Albumin ratio, fatty acids were expressed as ratios. No significant relationship was found between the PUFA/SFA ratio and proteins evaluated, probably because these lipid classes include many fatty acids which have different properties. On the other hand, $n-6 / n-3$ ratio and AA/EPA ratio were positively correlated with ORM, suggesting a proinflammatory role of n-6 PUFA. In fact, high serum proportions of n-6 PUFA and n-6/n-3 ratio are associated with 
the development of many diseases, including cardiovascular diseases, cancer, and inflammatory and autoimmune diseases [58].

About the study's limitations, it should be taken into account that the analysis is limited by the cross-sectional design, which does not allow the determination of temporal relationships. Moreover, we recognize that studies with greater sample size would be appropriate, controlling for potential confounding factors such as sex, smoking status, and age.

In conclusion, our findings suggest that serum fatty acids are linked to acute phase proteins in morbidly obese patients. Given that most significant associations have occurred with ORM, this protein may be the preferable marker to use in studies investigating relationships between serum fatty acids and low-grade inflammation. Despite these findings, further studies are also needed to confirm and explain the associations with acute phase proteins and total serum fatty acid composition, particularly in morbidly obese patients.

\section{Conflict of Interests}

No conflict of interests needs to be reported. The University Hospital had no role in the analysis or interpretation of the data or in the decision to submit the report for publication.

\section{Authors' Contribution}

Conception and study design: Ricardo Fernandes and Erasmo Benício Santos de Moraes Trindade. Acquisition of data: Ricardo Fernandes and Raphael Salles Granato Cunha. Analysis and interpretation of data: Ricardo Fernandes, Carolina de Quadros Camargo, Bruna Teles Soares Beserra, Elaine Hillesheim, Raphael Salles Granato Cunha and Erasmo Benício Santos de Moraes Trindade. Drafting of the manuscript: Ricardo Fernandes and Bruna Teles Soares Beserra. Statistical analysis: Ricardo Fernandes, Bruna Teles Soares Beserra and Elaine Hillesheim. Critical review of the intellectual content and final approval of the version to be published: Everson Araújo Nunes and Erasmo Benício Santos de Moraes Trindade. Material, technical and administrative support: Ricardo Fernandes, Raphael Salles Granato Cunha, Elaine Hillesheim, Danielle Cristina Tonello Pequito, Isabela Coelho, Luiz Cláudio Fernandes and Erasmo Benício Santos de Moraes Trindade. Study supervision: Ricardo Fernandes, Raphael Salles Granato Cunha, Elaine Hillesheim and Erasmo Benício Santos de Moraes Trindade.

\section{Acknowledgments}

The authors are grateful to the Multidisciplinary Integrated Residency Program in Health at the University Hospital of Federal University of Santa Catarinaby for the assistance with patients and blood sample logistic. This work was supported by the University Hospital of Federal University of Santa Catarina.

\section{References}

[1] World Health Organization, "Factsheet: obesity and overweight," 2012, http://www.who.int/mediacentre/factsheets/fs311/ en/index.html.

[2] S. H. Belle, W. Chapman, A. P. Courcoulas et al., "Relationship of body mass index with demographic and clinical characteristics in the Longitudinal Assessment of Bariatric Surgery (LABS)," Surgery For Obesity and Related Diseases, vol. 4, pp. 474-480, 2008.

[3] L. Sjöström, K. Narbro, C. D. Sjöström et al., "Effects of bariatric surgery on mortality in Swedish obese subjects," The New England Journal of Medicine, vol. 357, no. 8, pp. 741-752, 2007.

[4] R. Padwal, S. Klarenbach, N. Wiebe et al., "Bariatric surgery: a systematic review and network meta-analysis of randomized trials," Obesity Reviews, vol. 12, no. 8, pp. 602-621, 2011.

[5] S. Galic, J. S. Oakhill, and G. R. Steinberg, "Adipose tissue as an endocrine organ," Molecular and Cellular Endocrinology, vol. 316, no. 2, pp. 129-139, 2010.

[6] A. R. Johnson, J. J. Milner, and L. Makowski, “The inflammation highway: metabolism accelerates inflammatory traffic in obesity," Immunological Reviews, vol. 249, pp. 218-238, 2012.

[7] A. C. M. Thiébaut, M. Rotival, E. Gauthier et al., "Correlation between serum phospholipid fatty acids and dietary intakes assessed a few years earlier," Nutrition and Cancer, vol. 61, no. 4, pp. 500-509, 2009.

[8] L. Hodson, C. M. Skeaff, and B. A. Fielding, "Fatty acid composition of adipose tissue and blood in humans and its use as a biomarker of dietary intake," Progress in Lipid Research, vol. 47, no. 5, pp. 348-380, 2008.

[9] E. Warensjö, M. Öhrvall, and B. Vessby, "Fatty acid composition and estimated desaturase activities are associated with obesity and lifestyle variables in men and women," Nutrition, Metabolism and Cardiovascular Diseases, vol. 16, no. 2, pp. 128136, 2006.

[10] S. Caspar-Bauguil, A. Fioroni, A. Galinier et al., "Proinflammatory phospholipid arachidonic acid/eicosapentaenoic acid ratio of dysmetabolic severely obese women," Obesity Surgery, pp. 1-10, 2012.

[11] M. Micallef, I. Munro, M. Phang, and M. Garg, "Plasma n3 polyunsaturated fatty acids are negatively associated with obesity," British Journal of Nutrition, vol. 102, no. 9, pp. 13701374, 2009.

[12] J. Y. Kim, J. Y. Park, O. Y. Kim et al., "Metabolic profiling of plasma in overweight/obese and lean men using ultra performance liquid chromatography and Q-TOF Mass spectrometry (UPLC-Q-TOF MS)," Journal of Proteome Research, vol. 9, no. 9, pp. 4368-4375, 2010.

[13] K. Poudel-Tandukar, M. Sato, Y. Ejima et al., "Relationship of serum fatty acid composition and desaturase activity to Creactive protein in Japanese men and women," Atherosclerosis, vol. 220, no. 2, pp. 520-524, 2012.

[14] C. Klein-Platat, J. Drai, M. Oujaa, J.-L. Schlienger, and C. Simon, "Plasma fatty acid composition is associated with the metabolic syndrome and low-grade inflammation in overweight adolescents," American Journal of Clinical Nutrition, vol. 82, no. 6, pp. 1178-1184, 2005.

[15] L. Ferrucci, A. Cherubini, S. Bandinelli et al., "Relationship of plasma polyunsaturated fatty acids to circulating inflammatory 
markers," Journal of Clinical Endocrinology and Metabolism, vol. 91, no. 2, pp. 439-446, 2006.

[16] J.-M. Fernández-Real, M. Broch, J. Vendrell, and W. Ricart, "Insulin resistance, inflammation, and serum fatty acid composition," Diabetes Care, vol. 26, no. 5, pp. 1362-1368, 2003.

[17] H. Petersson, S. Basu, T. Cederholm, and U. Risérus, "Serum fatty acid composition and indices of stearoyl-CoA desaturase activity are associated with systemic inflammation: longitudinal analyses in middle-aged men," British Journal of Nutrition, vol. 99, no. 6, pp. 1186-1189, 2008.

[18] H. Petersson, L. Lind, J. Hulthe, A. Elmgren, T. Cederholm, and U. Risérus, "Relationships between serum fatty acid composition and multiple markers of inflammation and endothelial function in an elderly population," Atherosclerosis, vol. 203, no. 1, pp. 298-303, 2009.

[19] World Medical Association, "Ethical principles for medical research involving human subjects," Proceedings of the 59th WMA General Assembly, Seoul, Republic of Korea, October 2008, http://www.wma.net/en/30publications/10policies/b3/ index.html.

[20] T. B. Ledue, D. L. Weiner, J. D. Sipe, S. E. Poulin, M. F. Collins, and N. Rifai, "Analytical evaluation of particle-enhanced immunonephelometric assays for C-reactive protein, serum amyloid A and mannose-binding protein in human serum," Annals of Clinical Biochemistry, vol. 35, no. 6, pp. 745-753, 1998.

[21] F. D. Lasky, Z. M. C. Li, and D. D. Shaver, "Evaluation of a bromocresol purple method for the determination of albumin adapted to the DuPont aca discrete clinical analyzer," Clinical Biochemistry, vol. 18, no. 5, pp. 290-296, 1985.

[22] C. R. Correa, A. Y. O. Angeleli, N. R. Camargo, L. Barbosa, and R. C. Burini, "Comparison of CRP/albumin ratio with prognostic inflammatory nutritional index (PINI)," Jornal Brasileiro de Patologia e Medicina Laboratorial, vol. 38, pp. 183-190, 2002 (Portuguese).

[23] Y. Ingenbleek and Y. A. Carpentier, "A prognostic inflammatory and nutritional index scoring critically ill patients," International Journal for Vitamin and Nutrition Research, vol. 55, no. 1, pp. 91-101, 1985.

[24] J. Folch, M. Lees, and G. H. S. Stanley, "A simple method for the isolation and purification of total lipides from animal tissues," The Journal of biological chemistry, vol. 226, no. 1, pp. 497-509, 1957.

[25] T. G. Lohman, A. F. Roche, and R. Martorell, Anthropometric Standardization Reference Manual, Human Kinetics, Champaign, Ill, USA, 1998.

[26] World Health Organization, "Obesity: preventing and managing the global epidemic," Report of a WHO Consultation on Obesity, Geneva, Switzerland, 1998.

[27] Centers for Disease Control and Prevention (CDC), "Cigarette smoking among adults-United States, 1992, and changes in the definition of current cigarette smoking," Morbidity and Mortality Weekly Report, vol. 43, pp. 342-346, 1994.

[28] P. C. Calder, "Mechanisms of action of (n-3) fatty acids," Journal of Nutrition, vol. 142, no. 3, 2012.

[29] P. C. Calder, "Long-chain fatty acids and inflammation," The Proceedings of the Nutrition Society, vol. 71, pp. 284-289, 2012.

[30] R. K. Murumalla, M. K. Gunasekaran, J. K. Padhan et al., "Fatty acids do not pay the toll: effect of SFA and PUFA on human adipose tissue and mature adipocytes inflammation," Lipids in Health and Disease, vol. 11, article 175, 2012.

[31] F. Boesing, E. A. M. Moreira, D. Wilhelm-Filho et al., "Roux-enY bypass gastroplasty: markers of oxidative stress 6 months after surgery," Obesity Surgery, vol. 20, no. 9, pp. 1236-1244, 2010.

[32] S.-B. Chen, Y.-C. Lee, K.-H. Ser et al., "Serum C-reactive protein and white blood cell count in morbidly obese surgical patients," Obesity Surgery, vol. 19, no. 4, pp. 461-466, 2009.

[33] E. Pardina, R. Ferrer, J. A. Baena-Fustegueras et al., “The relationships between IGF-1 and CRP, NO, leptin, and adiponectin during weight loss in the morbidly obese," Obesity Surgery, vol. 20, no. 5, pp. 623-632, 2010.

[34] C. C. Wee, K. J. Mukamal, A. Huang, R. B. Davis, E. P. McCarthy, and M. A. Mittleman, "Obesity and C-reactive protein levels among white, black, and hispanic US adults," Obesity, vol. 16, no. 4, pp. 875-880, 2008.

[35] G. L. Myers, N. Rifai, R. P. Tracy et al., "CDC/AHA workshop on markers of inflammation and cardiovascular disease: application to clinical and public health practice: report from the laboratory science discussion group," Circulation, vol. 110, no. 25, pp. 545-549, 2004.

[36] C. Schweiger, R. Weiss, E. Berry, and A. Keidar, "Nutritional deficiencies in bariatric surgery candidates," Obesity Surgery, vol. 20, no. 2, pp. 193-197, 2010.

[37] B. Ernst, M. Thurnheer, S. M. Schmid, and B. Schultes, "Evidence for the necessity to systematically assess micronutrient status prior to bariatric surgery," Obesity Surgery, vol. 19, no. 1, pp. 66-73, 2009.

[38] M. Bavaresco, S. Paganini, T. P. Lima et al., "Nutritional course of patients submitted to bariatric surgery," Obesity Surgery, vol. 20, no. 6, pp. 716-721, 2010.

[39] P. L. Turner, L. Saager, J. Dalton et al., "A nomogram for predicting surgical complications in bariatric surgery patients," Obesity Surgery, vol. 21, no. 5, pp. 655-662, 2011.

[40] Y. S. Lee, J. W. Choi, I. Hwang et al., "Adipocytokine orosomucoid integrates inflammatory and metabolic signals to preserve energy homeostasis by resolving immoderate inflammation," Journal of Biological Chemistry, vol. 285, no. 29, pp. 22174-22185, 2010.

[41] R. Anty, M. Dahman, A. Iannelli et al., "Bariatric surgery can correct iron depletion in morbidly obese women: a link with chronic inflammation," Obesity Surgery, vol. 18, no. 6, pp. 709$714,2008$.

[42] A. Iannelli, R. Anty, T. Piche et al., "Impact of laparoscopic rouxen-Y gastric bypass on metabolic syndrome, inflammation, and insulin resistance in super versus morbidly obese women," Obesity Surgery, vol. 19, no. 5, pp. 577-582, 2009.

[43] E. J. Cabrera, A. C. Valezi, V. D. A. Delfino, E. L. Lavado, and D. S. Barbosa, "Reduction in plasma levels of inflammatory and oxidative stress indicators after roux-en-Y gastric bypass," Obesity Surgery, vol. 20, no. 1, pp. 42-49, 2010.

[44] A. A. Alfadda, S. Fatma, M. A. Chishti et al., "Orosomucoid serum concentrations and fat depot-specific mRNA and protein expression in humans," Molecules and Cells, pp. 1-7, 2012.

[45] L. Hodson, C. M. Skeaff, and B. A. Fielding, "Fatty acid composition of adipose tissue and blood in humans and its use as a biomarker of dietary intake," Progress in Lipid Research, vol. 47, no. 5, pp. 348-380, 2008. 
[46] X. Liu, M. S. Strable, and J. M. Ntambi, "Stearoyl Coa desaturase 1: role in cellular inflammation and stress," Advances in Nutrition, vol. 2, pp. 15-22, 2011.

[47] I. B. King, R. N. Lemaitre, and M. Kestin, "Effect of a low-fat diet on fatty acid composition in red cells, plasma phospholipids, and cholesterol esters: investigation of a biomarker of total fat intake," American Journal of Clinical Nutrition, vol. 83, no. 2, pp. 227-236, 2006.

[48] A. Baylin, K. K. Mi, A. Donovan-Palmer et al., "Fasting whole blood as a biomarker of essential fatty acid intake in epidemiologic studies: comparison with adipose tissue and plasma," American Journal of Epidemiology, vol. 162, no. 4, pp. 373-381, 2005.

[49] Q. Sun, J. Ma, H. Campos, S. E. Hankinson, and F. B. Hu, “Comparison between plasma and erythrocyte fatty acid content as biomarkers of fatty acid intake in US women," American Journal of Clinical Nutrition, vol. 86, no. 1, pp. 74-81, 2007.

[50] J. Y. Lee, L. Zhao, H. S. Youn et al., "Saturated fatty acid activates but polyunsaturated fatty acid inhibits Toll-like receptor 2 dimerizes with Toll-like receptor 6 or 1," Journal of Biological Chemistry, vol. 279, no. 17, pp. 16971-16979, 2004.

[51] A. R. Weatherill, J. Y. Lee, L. Zhao, D. G. Lemay, H. S. Youn, and D. H. Hwang, "Saturated and polyunsaturated fatty acids reciprocally modulate dendritic cell functions mediated through TLR4," Journal of Immunology, vol. 174, no. 9, pp. 5390-5397, 2005.

[52] C. Erridge and N. J. Samani, "Saturated fatty acids do not directly stimulate toll-like receptor signaling," Arteriosclerosis, Thrombosis, and Vascular Biology, vol. 29, no. 11, pp. 1944-1949, 2009.

[53] E. Warensjö, J.-H. Jansson, T. Cederholm et al., "Biomarkers of milk fat and the risk of myocardial infarction in men and women: a prospective, matched case-control study," American Journal of Clinical Nutrition, vol. 92, no. 1, pp. 194-202, 2010.

[54] C. Maruyama, M. Yoneyama, N. Suyama et al., "Differences in serum phospholipid fatty acid compositions and estimated desaturase activities between Japanese men with and without metabolic syndrome," Journal of Atherosclerosis and Thrombosis, vol. 15, no. 6, pp. 306-313, 2008.

[55] H. Wang, L. M. Steffen, B. Vessby et al., "Obesity modifies the relations between serum markers of dairy fats and inflammation and oxidative stress among adolescents," Obesity, vol. 19, no. 12, pp. 2404-2410, 2011

[56] Y. Zhao, S. Joshi-Barve, S. Barve, and L. H. Chen, "Eicosapentaenoic acid prevents LPS-induced TNF-alpha expression by preventing NF-kappaB activation," Journal of the American College of Nutrition, vol. 23, no. 1, pp. 71-78, 2004.

[57] M. Di Nunzio, F. Danesi, and A. Bordoni, "N-3 PUFA as regulators of cardiac gene transcription: a new link between ppar activation and fatty acid composition," Lipids, vol. 44, no. 12, pp. 1073-1079, 2009.

[58] A. P. Simopoulos, "The importance of the omega-6/omega3 fatty acid ratio in cardiovascular disease and other chronic diseases," Experimental Biology and Medicine, vol. 233, no. 6, pp. 674-688, 2008. 


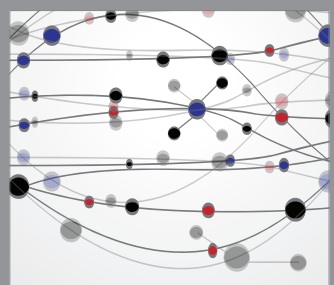

The Scientific World Journal
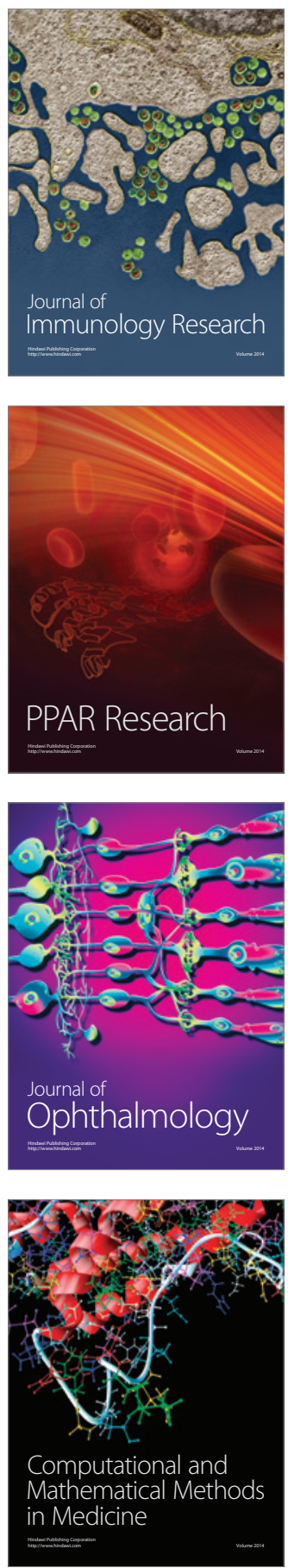

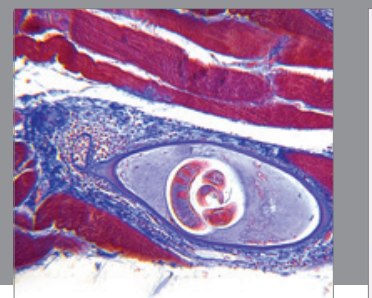

Gastroenterology

Research and Practice
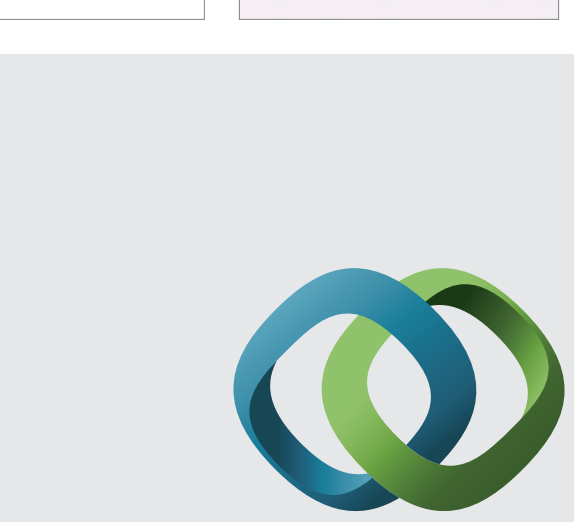

\section{Hindawi}

Submit your manuscripts at

http://www.hindawi.com
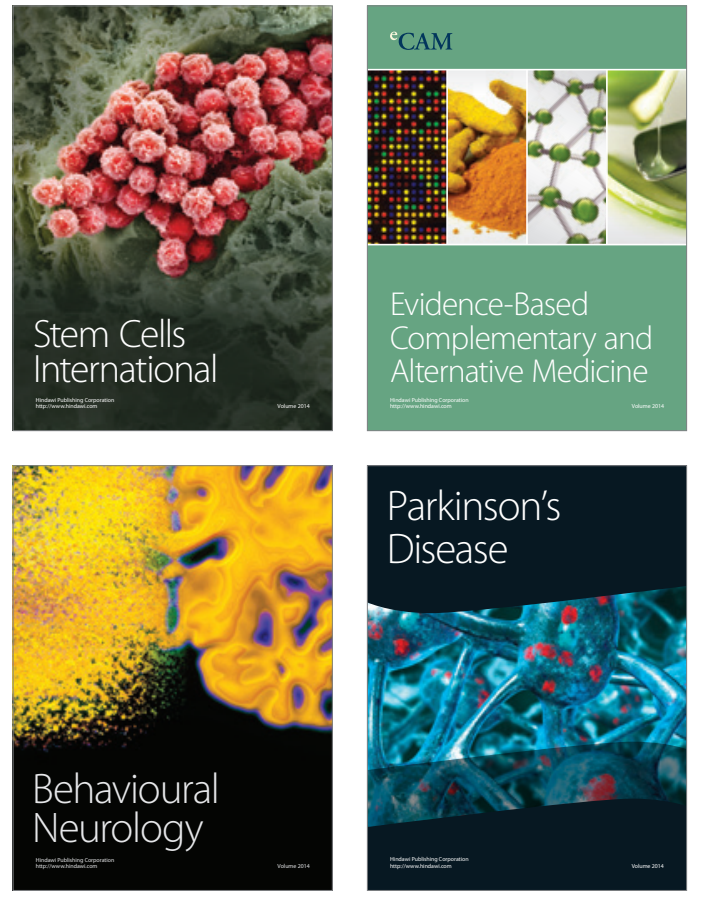
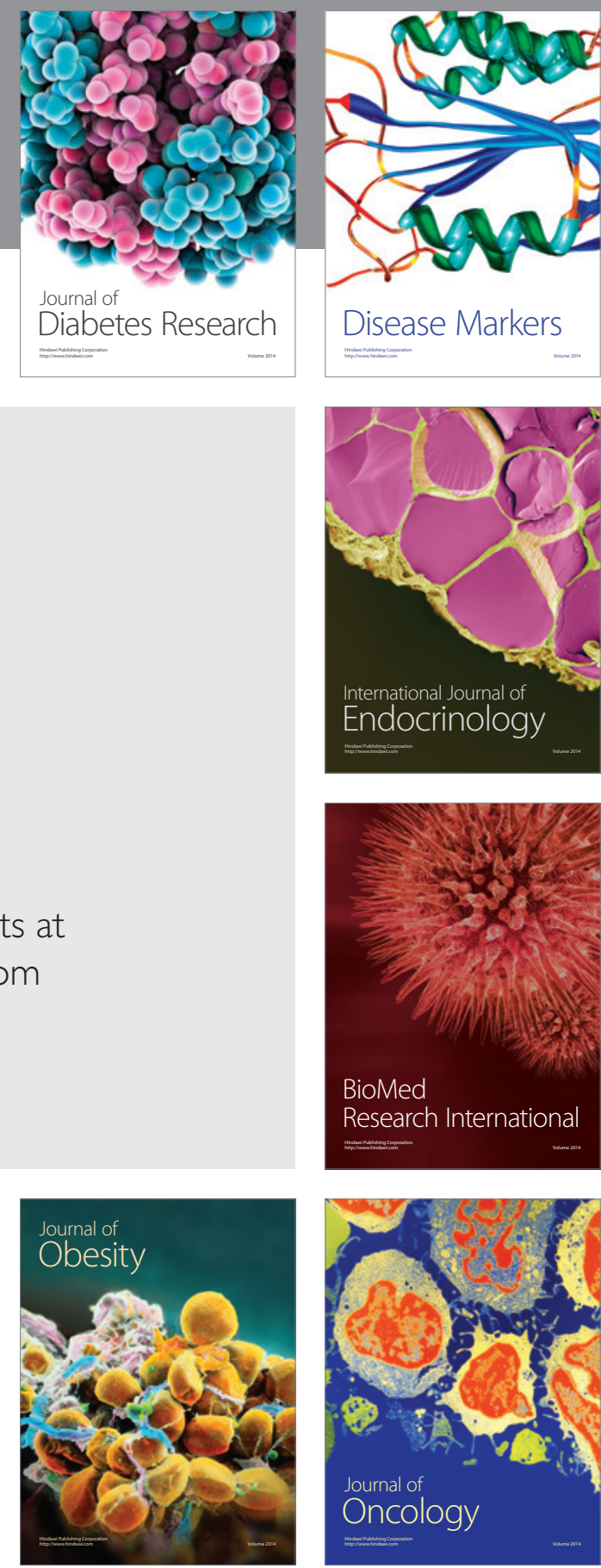

Disease Markers
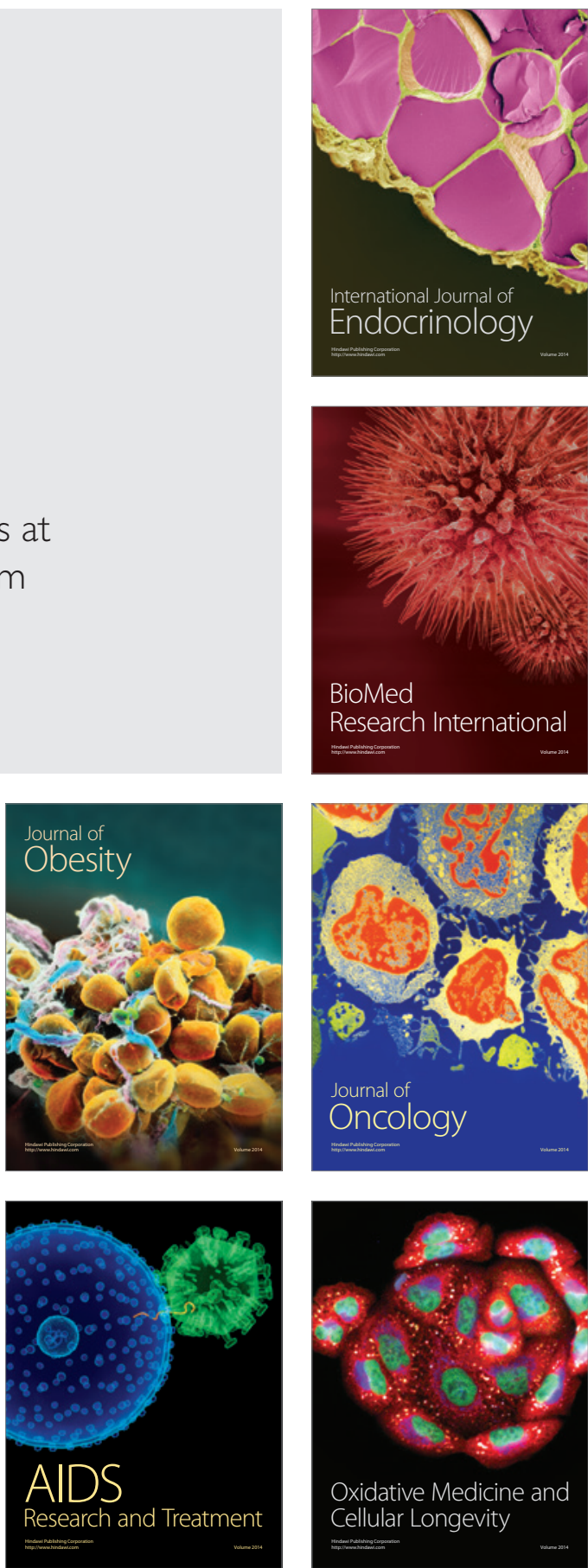